\title{
Applied Neuroeconomics: Science Meets Business Practice-Profound Insights or Witchcraft? (Abstract)
}

\author{
Klaus-Peter Wiedmann, Gesa Lischka, and Michael Schiessl
}

\begin{abstract}
In marketing in general and brand-related communication in particular, progress in neuroeconomics provided advanced tools to measure the impact of marketing activities and generated new findings and evidence for intuitive "gut knowledge" with reference to the performance of marketing activities. Consequently, high expectations in neuroeconomics generally and in neuroimaging technology particularly raised the hopes of marketers that their (daily business) problems could be solved, e.g., by improving marketing activities (pricing strategies, product packaging design, etc.) or uncovering insights about customer's true preferences. Moreover, neuroeconomics findings such as the winner-take-all/first-choice-brand effect, meaning that only the favored brand of a customer positively emotionalizes the decision-making process and therefore increases the buying probability, challenge the suitability of established marketing and marketing research concepts such as the evoked set. However, in the contemporary science and business world, the label "neuro" is overused, and an increasing number of companies sell neuro as a business activity (e.g., consulting, market research, etc.). With this tendency in mind, the aim of this paper is to discuss justifiable hopes from blind hype as well as to provide guidance for serious marketing purposes.
\end{abstract}

\footnotetext{
K.-P. Wiedmann $(\triangle)$

Leibniz University of Hannover, Hannover, Germany

e-mail: wiedmann@m2.uni-hannover.de

G. Lischka

Kochstrasse $^{\mathrm{TM}}$-Agentur für Marken $\mathrm{GmbH}$, Hannover, Germany

e-mail: lischka@kochstrasse.de

M. Schiessl

eye square $\mathrm{GmbH}$, Berlin, Germany

e-mail: schiess1@eye-square.com
} 